\title{
Correction to: Molecular analysis of maize (Zea mays L.)-infecting mastreviruses in Ethiopia reveals marked diversity of virus genomes and a novel species
}

\author{
Demsachew Guadie $^{1}\left[\right.$ [ $\cdot$ Kassahun Tesfaye ${ }^{1,4} \cdot$ Dennis Knierim $^{2} \cdot$ Stephan Winter $^{2} \cdot$ Adane Abraham $^{3}$
}

Published online: 8 April 2019

(c) Springer Science+Business Media, LLC, part of Springer Nature 2019

\section{Correction to: Virus Genes \\ https://doi.org/10.1007/s11262-019-01655-1}

The original version of this article unfortunately contained errors in the "Results" section.

In the "Detection and reconstruction of mastreviruses genomes" subsection, the word 'third' and 'three' indicating the underlined nucleotide position for $\underline{\mathrm{C}}$ and $\underline{\mathrm{G}}$ should be changed to 'fourth' and 'four' respectively. Hence, the correct text reads as follows:

"Only the conserved nonanucleotide sequence TAATAT $\mathrm{T} \downarrow \mathrm{AC}$ is diverse in MSDV with nucleotide mutations at the fourth and the eighth positions (underlined, TAA서T $\downarrow \underline{G}$ ) of this most conserved sequence in geminiviruses. Interestingly this unusual feature is also evident in Sweet potato symptomless virus 1 (SPSMV-1) with a nonanucleotide mutation at positions four and eight resulting in TAA GATT $\downarrow \underline{C} C$ motif."

In the "Distribution and incidence of mastreviruses infecting maize in Ethiopia" subsection, 'August' should be changed to 'September'. The correct sentence reads as:

The original article can be found online at https://doi.org/10.1007/ s11262-019-01655-1.

Demsachew Guadie

demsachew.guadie@aau.edu.et

1 Institute of Biotechnology, Addis Ababa University, P.O.Box 1176, Addis Ababa, Ethiopia

2 Leibniz Institute DSMZ-German Collection of Microorganisms and Cell Cultures, Inhoffenstrasse 7B, 38124 Brunswick, Germany

3 Department of Biotechnology, Addis Ababa Science and Technology University, Addis Ababa, Ethiopia

4 Ethiopian Biotechnology Institute, Ministry of Innovation and Technology, Addis Ababa, Ethiopia
"As revealed from PCR results, both MSV (100\%) and MSRV (36\%) have higher incidence in samples collected during September 2015 (late main rain feed cropping season) but ..."

The original article has been corrected. 